Number of pages: 21

Number of Figures: 8

Number of Tables: 4

Number of References: 24

\title{
Effects of seating on the discomfort caused by mechanical shocks: Measurement and prediction of SEAT values
}

\author{
Giulia Patelli and Michael J. Griffin \\ Human Factors Research Unit \\ Institute of Sound and Vibration Research \\ University of Southampton, \\ Southampton SO17 1BJ \\ England
}

Address for correspondence:

Emeritus Professor Michael J Griffin

e-mail: M.J.Griffin@soton.ac.uk

Telephone: +44 (0)23 80592277

Facsimile: +44 (0)23 80592927

\section{Running Head}

Discomfort from shocks when sitting on a soft seat 


\section{Highlights}

- SEAT values indicate the influence of seats on vibration discomfort

- SEAT values appear useful for both vibration and mechanical shock

- SEAT values can be measured subjectively or objectively or predicted by a model

- Low frequency high magnitude shocks merit further investigation 


\begin{abstract}
Seat effective amplitude transmissibilities (SEAT values) quantify the influence of seats on discomfort caused by vibration. This study investigated SEAT values with vertical mechanical shocks at low, medium, and high magnitudes $\left(0.5,1.0\right.$, and $\left.2.0 \mathrm{~ms}^{-1.75}\right)$ at frequencies between 1.0 and $16 \mathrm{~Hz}$. With 18 subjects sitting on a rigid seat and two foam cushions, SEAT values were measured objectively (from the transmitted vibration), measured subjectively (by the responses of subjects), and predicted (using a model of the seat-passenger system). Except with high magnitude low frequency shocks, predicted SEAT values were similar to measured SEAT values. With shocks causing subjects to rise off a cushion and subsequently impact the cushion (low frequencies around $1 \mathrm{~g}$ ), subjective SEAT values were better estimated using predicted SEAT values than objectively measured SEAT values, because accelerometers on cushions exaggerated the impact of the falling subject. However, accelerometers on rigid seats will underestimate such impacts.
\end{abstract}

Keywords: seat vibration; mechanical shocks; biodynamic modelling. 


\section{Introduction}

The discomfort caused by vertical vibration has been investigated for people sitting on a simple rigid flat seat (e.g. Miwa, 1967; Griffin et al. 1982; Morioka and Griffin, 2006; Zhou and Griffin, 2014) and standing on a floor (Thuong and Griffin, 2011a,b). Other studies have investigated the discomfort caused by vertical mechanical shocks (Matsumoto and Griffin, 2005; Ahn and Griffin, 2008; Zhou and Griffin, 2017). Some studies have investigated the effect of seat characteristics on the discomfort caused by vertical vibration (Whitham and Griffin, 1977; Corbridge and Griffin, 1986; Ebe and Griffin, 2000; Basri and Griffin, 2014) but there are no known systematic studies of the effects of seat dynamics on the discomfort caused by vertical mechanical shocks.

The SEAT value ('seat effective amplitude transmissibility' value) is an indicator of the isolation efficiency of a seat (Griffin, 1978, 2007). A SEAT value indicates the extent to which a seat increases or decreases the discomfort caused by vibration. A SEAT value of $100 \%$ (or 1.0 ) indicates that the dynamic response of a seat neither increases nor decreases vibration discomfort. A SEAT value greater than $100 \%$ indicates the seat increases vibration discomfort and a SEAT value less than $100 \%$ indicates the seat reduces vibration discomfort. The SEAT value is an indication of how the vibration discomfort experienced in a seat compares with the vibration discomfort when sitting in a rigid seat, so a rigid seat has a SEAT value of $100 \%$. A SEAT value less than $100 \%$ is desirable, but resonances in seat cushions or seat frames often result in SEAT values greater than $100 \%$. A SEAT value is a measure of how a seat influences the discomfort caused by a specific vibration on the surface supporting the seat: it depends on the input vibration (e.g., spectrum of floor vibration), the transmission of vibration though the seat (e.g., seat transmissibility), and the frequency-dependence of vibration discomfort (e.g., the frequency weighting for vibration discomfort).

A SEAT value can be determined in several ways. A 'measured SEAT value' can be determined if there are adequate ways of predicting discomfort from measurements of vibration on a seat and simultaneous measurements of vibration beneath the seat (assuming the vibration beneath a seat is the vibration that would be experienced when sitting on a rigid seat). A 'predicted SEAT value' can be determined if there is an adequate method of predicting the vibration on the surface of a seat from the vibration beneath the seat and understanding of the dynamic interaction between the seat and the human body (i.e., a suitable dynamic model of the seat-person system). A 'subjective SEAT value' can be determined by dividing subjective judgements of vibration discomfort (on a ratio scale) obtained when sitting on a seat by similar subjective judgements of vibration discomfort obtained when sitting on a rigid seat or when sitting 'on the floor' beneath the seat, although both of these are often impractical in a vehicle. 
Since, by definition, a SEAT value should indicate how much a seat increases or decreases vibration discomfort, a 'measured SEAT value' and a 'predicted SEAT value' are only useful if they correspond to 'subjective SEAT values'. This paper investigates differences between the three alternative SEAT values when a seat is exposed to vertical mechanical shocks

\section{Measured SEAT values}

Measured SEAT values can be obtained from the measured vibration by assuming vibration discomfort when sitting in a seat can be estimated using weightings derived from research or those incorporated in standards (Griffin, 1978; British standards Institution, 1987; International Organization for Standardization, 1997). For continuous vertical vibration, the 'measured SEAT value' of a seat cushion with no backrest can be given by the frequency-weighted r.m.s. acceleration between the cushion and the person divided by the frequency-weighted r.m.s. acceleration on the surface supporting the cushion. When there is contact with the backrest of a seat, the discomfort caused by backrest vibration needs to be included (Basri and Griffin, 2014), and the discomfort caused by vibration at the feet sometimes merits consideration (Griffin, 2007). The frequency-weighted acceleration at all the locations where there is input of significant vibration to the body has to be calculated in order to obtain a representative SEAT value for the axis of vibration excitation of interest. If there is significant vibration in other axes (either beneath the seat or on the seat), their contributions to vibration discomfort should also be included. For a complete consideration of the effect of a seat on vibration discomfort, the overall frequency-weighted r.m.s. acceleration should be calculated over all axes of excitation beneath the seat (fore-and-aft, lateral, vertical, roll, pitch, and yaw) and for all locations of input of vibration to the human body. The overall SEAT value will then show how the multi-frequency, multi-axis, multi-input vibration experienced on a seat compares with that on a rigid seat in the same vibration environment.

High correlations have been reported between subjective responses and the measured SEAT values of 16 car seats (van Nierkerk et al., 2003). In a laboratory study with cushions at both the seat pan and a reclined backrest, it was found that 'subjective SEAT values' were similar to 'measured SEAT values' (calculated according to current standards) for three seats of different 'hardness' when exposed to vertical vibration at each of the one-third octave centre frequencies over the frequency range 1 to $20 \mathrm{~Hz}$ (Basri and Griffin, 2014). Some statistically significant differences at low and high frequencies were partially explained by assumptions and limitations in the currently standardised methods for predicting vibration discomfort.

If an oscillatory motion contains shocks, the method of predicting vibration discomfort and SEAT values should be appropriate for shock (e.g., the vibration dose value, VDV). With vertical mechanical shocks applied to a person through a cushion, the measured SEAT value 
of the cushion might be estimated as the ratio between the VDV of the acceleration measured on the seat beneath the person and the VDV of the acceleration measured on the rigid support beneath the cushion (Griffin, 2007):

$$
\text { SEAT } \%=\frac{V D V_{\text {beneath person }}}{V D V_{\text {beneath cusion }}} \times 100
$$

where both VDVs are frequency-weighted using the weighting applicable to vibration at the seat-person interface.

Measured SEAT values are being used to predict the isolation efficiency of seats where mechanical shocks are dominant. However, there are no known studies investigating whether they provide good indications of the effects of a seat on the perceived severity of shocks.

\section{Predicted SEAT values}

When a person sits on a non-rigid conventional seat, the transmission of vibration through the seat depends on the dynamic characteristics of both the seat and the human body. Great complexities are possible when modelling the dynamics of seats and the dynamics of the human body, but very simple models can provide good predictions and illustrate the principles (Toward and Griffin, 2011). A 3-degree-of-freedom model of the coupled seat and human body system can predict both the modulus and the phase of vertical seat transmissibility for vibration in the range $1.25 \mathrm{~Hz}$ to $25 \mathrm{~Hz}$ (Wei and Griffin, 1998). A 1-degree-of-freedom model and a 2degree-of-freedom model can predict the vertical forces applied to the body when sitting on a rigid seat with vertical mechanical shocks having peak accelerations less than about $1 \mathrm{~g}$ (Zhou and Griffin, 2017b), but such models have not been used to predict the transmission of shocks though seats and their effects on discomfort.

Seating dynamics can be determined from measurements of seat transmissibility or by measuring the seat response in a test rig and representing its dynamic stiffness by a spring and a damper, with or without frequency-dependent stiffness and hysteric damping (Tufano and Griffin, 2017). If the appropriate dynamics of the human body are known, the stiffness and damping of the seat can then be used in a model to predict seat transmissibility.

Although the dynamics of the human body exposed to vertical excitation can be represented by 1- or 2-degree-of-freedom models (Toward and Griffin, 2011; Wei and Griffin, 1998; Fairley and Griffin, 1989), the body has a nonlinear response in which the resonance frequency decreases with increasing magnitude of excitation. With vertical mechanical shocks, linear 1and 2-degree-of freedom models can also provide good fits to the measured biodynamic response of the body, but the optimum stiffness and optimum damping of the models vary with both the nominal frequency of the shocks $(1$ to $16 \mathrm{~Hz}$ ) and the magnitude of the shocks (up to \pm 8.3 ms $^{-2}$ r.m.s.) (Zhou and Griffin, 2017b). There are no known investigations of linear models 
for predicting mechanical shocks experienced when sitting on soft seats and no known studies of the applicability of a linear model for predicting the SEAT value of a seat exposed to mechanical shock.

\section{Objectives and hypotheses}

The main objective of this study was to understand the transmission of vertical shocks through a seat cushion supporting the human body. The study investigated the extent to which the severity of shocks experienced when sitting on a cushion could be predicted using a simple lumped parameter model optimised to the dynamic response of the seat-body system to continuous random vibration. The study also compared the accuracy of measured and predicted SEAT values.

When the magnitude of a vertical mechanical shock on a seat surface approaches $1 \mathrm{~g}$, the human body will 'leave' the seat and subsequently impact with the seat. It was hypothesised that this will cause the 'measured SEAT value' (i.e., the ratio of the measured frequencyweighted VDV on a cushion to the measured frequency-weighted VDV beneath the cushion) to overestimate the true SEAT value. It is assumed that the true SEAT value will be the 'subjective SEAT value': the ratio of magnitude estimates of discomfort experienced when sitting on the seat cushion to magnitude estimates of discomfort experienced when sitting on the rigid seat without the cushion. The overestimation in SEAT values with high acceleration shocks will arise because the acceleration measured on the cushion will contain an artefact caused by the impact of the falling subject. For these situations, it was hypothesised that the 'predicted SEAT value' (predicted from a 3-degree-of-freedom model of the cushion and the human body optimised to the transmissibility of the cushion with random vibration) would provide a more accurate estimate of the 'subjective SEAT value' (i.e., the true SEAT value) than the 'measured SEAT value'.

\section{Method}

\subsection{Subjects}

Eighteen male students and staff of the University of Southampton participated in the study (age: 20 to 38 years; stature: 161 to $187 \mathrm{~cm}$; mass: 65 to $105 \mathrm{~kg}$ ). The sitting masses of the eighteen subjects (i.e., the mass supported on a Kistler force plate at the seat surface) fell in the range 44 to $76 \mathrm{~kg}$. The experiment was approved by the Ethics Committee of the Faculty of Engineering and the Environment at the University of Southampton (Reference number: 15158). 


\subsection{Apparatus}

A 1-m stroke electrohydraulic vibrator produced vertical mechanical shocks (Servotest Testing Systems Ltd., Surrey, UK). Stimuli were generated in HVLab Matlab Toolbox (version 2.0, ISVR, University of Southampton, UK) and then equalized to the response of the vibrator by a Servotest Pulsar system.

A rigid seat was mounted on the platform of the vibrator. The seat without foam was assumed to be 'rigid', even when subjected to a subject falling on the seat, because it was rigidly secured to the vibrator platform having a mass of approximately $1000 \mathrm{~kg}$. The seat had an upright backrest but subjects did not make contact with the backrest. The horizontal supporting seat surface was $41 \mathrm{~cm}$ above the vibrator platform supporting the feet and $71 \mathrm{~cm}$ wide by $51 \mathrm{~cm}$ deep.

Three seating conditions were investigated:

(i) subjects sat on the rigid seat;

(ii) subjects sat on a block of polyurethane foam $40 \mathrm{~mm}$ thick supported on the rigid seat;

(iii) subjects sat on a block of polyurethane foam $80 \mathrm{~mm}$ thick supported on the rigid seat.

The two blocks were made of the same foam had upper and lower surfaces $380 \mathrm{~mm} \times 380$ $\mathrm{mm}$. Doubling the thickness of the foam $(40$ to $80 \mathrm{~mm}$ ) will have reduced the dynamic stiffness of the foam and also reduced the damping of the foam (Rezali and Griffin, 2016).

The acceleration at the base of the rigid seat was measured by a capacitive accelerometer 2260-002 (Silicon Designs Inc.). The acceleration on the top surface of the foam was measured using a SIT-pad with an integrated tri-axial accelerometer (Willow Technologies KXD94-2802). When calculating SEAT values, the measured acceleration time-histories were frequencyweighted using frequency weighting $W_{b}$ (BS 6841: 1987).

A noise generator (HFRU Noise system 001, ISVR, University of Southampton, UK) produced white noise at $70 \mathrm{dBA}$ via a pair of headphones so as to mask any variations in noise.

\subsection{Shock stimuli}

The stimuli were vertical mechanical shocks with fundamental frequencies at the 13 preferred one-third octave centre frequencies in the range 1 to $16 \mathrm{~Hz}$. The shocks were formed from $1 \frac{1}{2}$ cycles of a sinusoid of the required fundamental frequency multiplied by a half cosine over the duration of the $11 / 2$-cycle sinusoid. As shown in Figure 1 , the peak acceleration was always downward, corresponding to an upward displacement. The displacement initially always 
moved upwards and then downwards back to the starting position. The durations of the shocks depended on their fundamental frequency, decreasing from $1.5 \mathrm{~s}$ at $1.0 \mathrm{~Hz}$ to $0.09 \mathrm{~s}$ at $16 \mathrm{~Hz}$.

\section{FIGURE 1 ABOUT HERE}

Subjects were exposed to 117 stimuli: 13 fundamental frequencies at three magnitudes in three seat conditions. The magnitudes of the shock motions were expressed in terms of their $W_{\mathrm{b}}$ weighted vibration dose value, VDV, as defined in BS 6841:1987 (British Standards Institution, 1987). Three magnitudes were presented in $6 \mathrm{~dB}$ steps of frequency-weighted VDV: $0.5 \mathrm{~ms}^{-1.75}$ (low magnitude), $1.0 \mathrm{~ms}^{-1.75}$ (middle magnitude) and $2.0 \mathrm{~ms}^{-1.75}$ (high magnitude). At each of the three magnitudes, the frequency weighting and the duration weighting incorporated within the calculation of vibration dose values meant that shocks with different fundamental frequencies were expected to produce broadly similar discomfort when experienced on the rigid seat. The use of frequency weighting $W_{\mathrm{g}}$ in place of frequency-weighting $W_{\mathrm{b}}$ would have slightly changed some of the SEAT values but not altered the conclusions to the study. The unweighted peak accelerations at each magnitude and at each fundamental frequency are shown in Table 1.

\section{TABLE 1 ABOUT HERE}

The daily exposures experienced by vehicle drivers summarise the severity of an accumulation of many hours of exposure and can have far greater vibration dose values than those of the individual shocks simulated in this study. The individual shocks presented in the experiment were reasonably representative of the individual shocks experienced by professional drivers. The accumulation of exposure to vibration and many such shocks produces the greater vibration dose values for their daily exposures. The simulation of individual shocks with the same vibration dose value as a daily exposure to vibration and shock would not have represented the real situation.

\subsection{Procedure}

Subjects attended one session of approximately 1 hour split into three parts, one part for each seat condition.

Subjects sat in an upright posture without touching the backrest (Figure 1). They rested their hands on their laps and kept their eyes closed during exposure to shocks (so that seeing their movement relative to the laboratory could not affect their judgements about feeling the motions). The feet were supported on a flat rigid footrest that was adjusted so that the angles between the upper and lower legs were about 95 degrees, so as to minimise contact between thighs and seat. Subjects wore headphones presenting $70 \mathrm{~dB}(\mathrm{~A})$ white noise during the entire 
duration of the experiment. For safety purposes, subjects wore a loose lap belt and they were provided with an emergency button that could stop the motion of the vibrator.

Subjects were instructed to give a numerical rating to the discomfort produced by the first shock they experienced. They judged the discomfort caused by subsequent shocks in proportion to the discomfort caused by the first shock using absolute magnitude estimation. They were free to start with any number, although 100 was suggested. The first shock was 4 $\mathrm{Hz}$ at $1.0 \mathrm{~ms}^{-1.75}\left(W_{\mathrm{b}}\right.$ weighted VDV). Prior to the experiment, subjects were trained on the method of absolute magnitude estimation by rating the apparent lengths of lines drawn on paper and judging the discomfort caused by practice stimuli (10 shocks encompassing the range of frequencies and magnitudes presented during the experiment). All 117 magnitude estimates from each individual subject were subsequently normalised by dividing by the median of the magnitude estimates from that subject and then multiplying by 100 . If subjects felt that a shock caused them to lift off the seat they informed the experimenter who could also observe the separation and see a spike in the force plate on the seat as the subject subsequently impacted on the seat.

After being exposed to mechanical shocks in all three seating conditions, subjects sat on each of the two foam cushions in turn while they were exposed to 60-s broadband random vertical vibration with a flat constant bandwidth acceleration power spectral density in the range 0.5 to $25 \mathrm{~Hz}$ presented at three magnitudes: $0.5,1.0$, and $2.0 \mathrm{~ms}^{-2}$ r.m.s. With a frequency resolution of $0.125 \mathrm{~Hz}$, the vertical transmissibility, $H(f)$, of both foam cushions were calculated from the cross power spectral density, $G_{i o}(f)$ of the input (vertical acceleration at the rigid seat base) and the output (vertical acceleration on the top surface of the foam cushion beneath the subject's ischial tuberosities) and the power spectral density of the input acceleration, $G_{i i}(f)$ :

$$
H(f)=\frac{\operatorname{Gio}(f)}{\operatorname{Gii}(f)}
$$

\subsection{Model of the coupled human body and seat system}

A three degree-of-freedom model was used to represent the coupled seat and human body system (Figure 2). The parameters of the model $m_{1}, m_{2}$, and $m_{3}$ represent masses of the human body, $k_{1}$ and $k_{2}$ and $k_{3}$ represent stiffnesses of the block of foam and the human body, $c_{1}$ and $c_{2}$ and $c_{3}$ represent the damping of the block of foam and the human body (Wei and Griffin, 1998; Tufano and Griffin, 2013).

\section{FIGURE 2 ABOUT HERE}

The equations of motion of the model were solved both in the time domain and in the frequency domain. 
The equations of motion were solved in the frequency domain in order to find the optimum parameters of the model. The function fmincon of MATLAB R2014a (MathWorks, Massachusetts, U.S.A.) was used to find the parameters that minimized an error function between the measured vertical seat transmissibility and the vertical seat transmissibility predicted by the three degree-of-freedom model (Wei and Griffin, 1998). The error function was the root-mean-square error between the real parts and the imaginary parts of the measured and the predicted vertical transmissibility (equation 1):

$$
\begin{gathered}
\text { Error }= \\
\sqrt[2]{\text { mean }\left(\sum\left(\operatorname{Re}\left\{Z(f)_{\text {predicted }}\right\}-\operatorname{Re}\left\{Z(f)_{\text {measured }}\right\}\right)^{2}+\sum\left(\operatorname{Im}\left\{Z(f)_{\text {predicted }}\right\}-\operatorname{Im}\left\{Z(f)_{\text {measured }}\right\}\right)^{2}\right)}
\end{gathered}
$$

The sum of the three masses, $m\left(=m_{1}+m_{2}+m_{3}\right)$, was adjusted to the sitting mass of each subject calculated from the modulus of their vertical apparent mass at $0.5 \mathrm{~Hz}$ measured on the rigid seat during to $60-\mathrm{s}$ of $0.5 \mathrm{~Hz}$ to $25 \mathrm{~Hz}$ random vibration at $1.0 \mathrm{~ms}^{-2}$ r.m.s.

The optimum parameters for the three degree-of-freedom model were found using the measured seat transmissibility at each of the three magnitudes $\left(0.5,1.0\right.$, and $2.0 \mathrm{~ms}^{-2}$ r.m.s. $)$ and used in the model to predict the response of the foam cushion with low, middle, and high magnitude mechanical shocks.

The optimum values of $m_{1}, m_{2}, m_{3}, k_{1}, k_{2}, k_{3}, c_{1}, c_{2}$ and $c_{3}$ were used to solve the three degreeof-freedom model in the time domain for predicting the responses of the two foam cushions to mechanical shocks. The equations of motion in the time domain were solved using the Runge - Kutta method.

\subsection{Subjective SEAT values, measured SEAT values, and predicted SEAT values}

A 'subjective SEAT value' was defined as the ratio between the magnitude estimate of discomfort given to a shock when sitting on a foam cushion ( $\left.\psi_{\text {cushion }}\right)$ to the magnitude estimate of discomfort given to the same shock when sitting on the rigid seat ( $\left.\psi_{\text {rigid seat }}\right)$ :

$$
\text { SEAT } T_{\text {subjective }} \%=\frac{\psi_{\text {cushion }}}{\psi_{\text {rigid seat }}} \times 100
$$

A 'measured SEAT value' was defined as the ratio between the VDV of the $W_{\mathrm{b}}$-weighted acceleration measured on the top surface of a foam cushion beneath the person to the VDV of the $W_{b}$-weighted acceleration measured beneath the foam cushion:

$$
S E A T_{\text {measured }} \%=\frac{V D V_{\text {measured beneath person }}}{V D V_{\text {measured beneath cushion }}} \times 100
$$


A 'predicted SEAT value' was defined as the ratio between the VDV calculated from the $W_{b^{-}}$ weighted value of the predicted acceleration, $a_{1}$, of the mass $m_{1}$ (Figure 2 ) and the VDV of the $W_{\mathrm{b}}$-weighted acceleration measured beneath the foam cushion:

$$
S E A T_{\text {predicted }} \%=\frac{V D V_{\text {predicted beneath person }}}{V D V_{\text {measured beneath cushion }}} \times 100
$$

\subsection{Statistical analysis}

The hypotheses were tested using non-parametric tests. Differences between related samples were investigated adopting the Friedman two-way analysis of variance and the Wilcoxon matched-pairs signed ranks test.

\subsection{Median percentage differences between measurements and predictions}

For each magnitude and fundamental frequency of mechanical shock, the difference between the predicted SEAT value and the measured SEAT value was given by the median percentage difference, $D$ :

$$
\mathrm{D}_{\text {measured_predicted }}=100 * \text { median }\left(\frac{\mathrm{SEAT}_{\mathrm{i}}^{\text {measured }}-\mathrm{SEAT}_{\mathrm{i}}^{\text {predicted }}}{\mathrm{SEAT}_{\mathrm{i}}^{\text {measured }}}\right)
$$

where $i$ refers to the $i^{\text {th }}$ subject. Similar expressions were used to express the error between subjective SEAT values and both the measured SEAT values and the predicted SEAT values.

\section{Results}

\subsection{Measured cushion transmissibility}

The two foam cushions had transmissibilities that differed and depended on the magnitude of the random vibration (Figure 3).

\section{FIGURE 3 ABOUT HERE}

With the 40-mm foam cushion, increasing the magnitude of random vibration reduced the resonance frequency in the median transmissibility from $4.5 \mathrm{~Hz}$ to $4 \mathrm{~Hz}(p<0.001$, Friedman; Figure 2). The transmissibility at resonance also depended on the magnitude of vibration $(p<0.001$, Friedman) and was lowest with the highest magnitude of vibration $(p<0.004$, Wilcoxon).

With the $80-\mathrm{mm}$ foam cushion, increasing the magnitude of random vibration reduced the resonance frequency in the median transmissibility from $4.0 \mathrm{~Hz}$ to $3.3 \mathrm{~Hz}(p<0.001$, Friedman; Figure 2). The transmissibility at resonance frequency did not depend on the magnitude of vibration ( $p=0.234$; Friedman). 


\subsection{Predicted vertical seat transmissibilities and predicted shock waveforms}

For an example subject (with a sitting mass close to the median sitting mass) and $1.0 \mathrm{~ms}^{-2}$ r.m.s. random vibration, the foam cushion transmissibilities fitted with the optimum 3-degreeof-freedom model are compared with the measured transmissibilities of the 40-mm and 80$\mathrm{mm}$ foam cushions in Figure 4. For all 18 subjects, both foams, and all three magnitudes of vibration there were close fits to both the modulus and the phase of the transmissibility.

\section{FIGURE 4 ABOUT HERE}

Example acceleration waveforms of shocks with fundamental frequencies of $2 \mathrm{~Hz}$ and $16 \mathrm{~Hz}$ predicted by the 3-degree-of-freedom model are compared with measured waveforms for the same subject in Figure 5.

When the downward acceleration at the top surface of the cushion reached about $1 \mathrm{~g}$ some shocks caused the human body to lift off the cushion and then subsequently impact with the SIT-pad on the cushion surface. The accelerometer in the SIT-pad indicated an impact in the acceleration time history that was not predicted by the simple 3-degree-of-freedom linear model. The measured VDV was then greater than the predicted VDV (Figure 4; top right).

\section{FIGURE 5 ABOUT HERE}

\subsection{Measured SEAT values compared with subjective SEAT values}

The subjective SEAT values showed variability among subjects with the low and middle magnitude shocks. For each subject, the measured, predicted, and subjective SEAT values at the central frequencies of $1 \mathrm{~Hz}, 2 \mathrm{~Hz}, 4 \mathrm{~Hz}, 8 \mathrm{~Hz}$, and $16 \mathrm{~Hz}$ were calculated as the average values over the frequencies in these octave bands. This procedure was repeated for each of the three magnitudes of vibration.

With the 40-mm foam cushion, the measured SEAT values were similar to the subjective SEAT values at most frequencies (Figure 6). However, the subjective SEAT values were less than the measured SEAT values with the lowest magnitude at $1 \mathrm{~Hz}(p=0.025)$. The subjective SEAT values were greater than the measured SEAT values with the middle magnitude at $16 \mathrm{~Hz}$ $(p=0.035)$. The subjective SEAT value was less than the measured SEAT value with the highest magnitude at 1 and $2 \mathrm{~Hz}(p<0.002)$. At the middle magnitude of vibration (weighted VDV $\left.=1.0 \mathrm{~ms}^{-1.75}\right)$ the median percentage differences were between about $-2 \%$ and $+8 \%$ over the range 1 to $8 \mathrm{~Hz}$ (Table 2). The greatest differences occurred with the greatest magnitudes of shock, where at frequencies less than $2 \mathrm{~Hz}$ the mean difference reached $40 \%$.

FIGURE 6 ABOUT HERE

TABLE 2 ABOUT HERE 
With the 80-mm foam cushion, the measured SEAT values were also similar to the subjective SEAT values at most frequencies with the low and middle magnitude shocks (Figure 6). However, subjective SEAT values were greater than measured SEAT values with the lowest magnitude at 8 and $16 \mathrm{~Hz}(p<0.005)$ and with the middle magnitude at $16 \mathrm{~Hz}(p=0.001)$. At the highest magnitude, the subjective SEAT values were less than the measured SEAT values at $1 \mathrm{~Hz}$ and $2 \mathrm{~Hz}(p<0.001)$, but greater at 8 and $16 \mathrm{~Hz}(p<0.001)$ (Table 2$)$.

\subsection{Predicted SEAT values compared with subjective SEAT values}

With the 40-mm foam cushion, the predicted SEAT values were similar to subjective SEAT values at most frequencies (Figure 6). However, the subjective SEAT values were less than the predicted SEAT values with the lowest shock magnitude at $1 \mathrm{~Hz}(p=0.007)$. The subjective SEAT values were greater than the predicted SEAT values with the middle shock magnitude at $16 \mathrm{~Hz}(p=0.025)$ and the highest shock magnitude at $16 \mathrm{~Hz}(p=0.028)$. With the middle and high magnitude shocks the median differences were between $-8 \%$ and $+9 \%$ over the range 1 to $8 \mathrm{~Hz}$ (Table 3).

\section{TABLE 3 ABOUT HERE}

With the $80-\mathrm{mm}$ foam cushion, the predicted SEAT values were also similar to the subjective SEAT values at most frequencies (Figure 6). Subjective SEAT values were less than the predicted SEAT values with the lowest shock magnitude at $1 \mathrm{~Hz}(p=0.031)$ and greater at 8 and $16 \mathrm{~Hz}(p<0.012)$. Subjective SEAT values were greater than the predicted SEAT values with the middle shock magnitude at $16 \mathrm{~Hz}(p=0.001)$ and with the greatest magnitude at $16 \mathrm{~Hz}$ $(p=0.004)$. Subjective SEAT values were lower than the predicted SEAT values with the greatest magnitude at $2 \mathrm{~Hz}(p<0.001)$. With low, middle, and high magnitude shocks the median differences were between $+2 \%$ and $+15 \%$ over the range 1 to $4 \mathrm{~Hz}$ (Table 3 ).

\subsection{Measured SEAT values compared with predicted SEAT values}

The predicted SEAT values were similar to the measured SEAT values with the low and middle magnitude shocks, but differed greatly with low frequency high magnitude shocks (Figure 7).

With the 40-mm foam cushion, the model predicted SEAT values for low and middle magnitude shocks with median percentage differences from the measured SEAT values less than $15 \%$ (Table 4). With high magnitude shocks the median percentage differences was also less than $15 \%$ for fundamental frequencies greater than $2.5 \mathrm{~Hz}$, but the difference increased to more than $30 \%$ at $1 \mathrm{~Hz}$ and $2 \mathrm{~Hz}$.

With the 40-mm foam cushion, the measured SEAT values were less than the predicted SEAT values with the lowest magnitude shocks from 1.0 to $2.0 \mathrm{~Hz}(p<0.002)$ but were greater at 16 $\mathrm{Hz}(p=0.043)$. The measured SEAT values were less than the predicted SEAT values with the 
middle magnitude shocks at $1.0,1.25$, and $2.5 \mathrm{~Hz}$ but greater at $16 \mathrm{~Hz}(p<0.0016)$. The measured SEAT values were greater than the predicted SEAT values with the greatest magnitude shocks from 1 to $2.5 \mathrm{~Hz}(p<0.001)$ but less from 5 to $8 \mathrm{~Hz}(p<0.008)$ (Figure 7$)$. Table 4 shows the median percentage difference between the measured and the predicted SEAT values for a 40-mm foam cushion. At the lowest magnitude and the middle magnitude the model was able to predict the SEAT values with a median percentage difference less than $15 \%$. At the highest magnitude, the median percentage differences were less than $15 \%$ at frequencies greater than $2.5 \mathrm{~Hz}$ but greater than $30 \%$ at frequencies from 1 to $2 \mathrm{~Hz}$.

\section{FIGURE 7 ABOUT HERE}

\section{TABLE 4 ABOUT HERE}

With the $80-\mathrm{mm}$ foam cushion, the model predicted SEAT values for low and middle magnitude shocks with median percentage differences less than $20 \%$ (Table 4 ). With high magnitude shocks, the median percentage difference was also less than $20 \%$ for fundamental frequencies greater than $4 \mathrm{~Hz}$ but the difference increased to more than $35 \%$ at $1.0,1.25,1.6$, and $2.0 \mathrm{~Hz}$. With the 80-mm foam cushion, there were significant differences between the measured SEAT values and the predicted SEAT values with the lowest magnitude shocks at all frequencies from 1 to $16 \mathrm{~Hz}(p<0.016)$, where the measured SEAT values were less than the predicted SEAT values, except at 1.25 and $2 \mathrm{~Hz}(p>0.064)$. With the middle magnitude shocks, the measured SEAT values were greater than the predicted SEAT values at all frequencies from $1 \mathrm{~Hz}$ to $1.6 \mathrm{~Hz}(p<0.043)$ but less from 2 to $16 \mathrm{~Hz}(p<0.039)$. With the greatest magnitude shocks, the measured SEAT values were greater than the predicted SEAT values from 1.0 to $2.0 \mathrm{~Hz}(p<0.001)$ and at 3.15 and $4.0 \mathrm{~Hz}(p<0.004)$, but less from 10 to $16 \mathrm{~Hz}(p<0.025)$ (Figure 7). Table 4 shows the median percentage differences between measured and predicted SEAT values for the $80-\mathrm{mm}$ foam cushion. At the lowest and the middle magnitudes of shock, the model was able to predict the SEAT values with a median percentage difference less than $20 \%$. At the greatest magnitude, the median percentage difference was less than $20 \%$ at frequencies greater than $4 \mathrm{~Hz}$ but greater than $35 \%$ at frequencies from 1 to $3.15 \mathrm{~Hz}$, except at $2.5 \mathrm{~Hz}$.

\section{Discussion}

\subsection{Subjective SEAT values}

The subjective SEAT values show differences between the discomfort caused by shocks when sitting on the foam cushions and when sitting on the rigid seat. The findings indicate that both the $40-\mathrm{mm}$ foam and the $80-\mathrm{mm}$ foam increased the discomfort caused by vertical shocks with 
fundamental frequencies in the range 1 to $4 \mathrm{~Hz}$ but reduced discomfort caused by shocks with fundamental frequencies in the range 8 to $16 \mathrm{~Hz}$ (Figure 6).

The subjective SEAT values are consistent with the foam amplifying vibration, especially at frequencies in the range 2 to $4 \mathrm{~Hz}$ (Figures 6; Tables 2 and 3). The frequency-dependence of the subjective SEAT values differ from the transmissibilities measured with broadband random vibration because each shock contained frequencies higher and lower than the fundamental frequency of the shock. Consequently, the foam did not double the discomfort for shocks having fundamental frequencies around the resonance frequency (e.g., $4 \mathrm{~Hz}$ ) and did not halve the discomfort for shocks having high fundamental frequencies (e.g. $16 \mathrm{~Hz}$ ).

\subsection{Effect of foam thickness on the subjective SEAT values}

The subjective SEAT values are compared for the two foam cushions in Figure 8. At frequencies from 1.0 to $4.0 \mathrm{~Hz}$ the discomfort caused by low magnitude and middle magnitude shocks was increased more by the $80-\mathrm{mm}$ foam than the $40-\mathrm{mm}$ foam. Doubling the thickness of a cushion roughly halves its stiffness and can increase the transmissibility at resonance, so explaining the greater discomfort on the $80-\mathrm{mm}$ foam with shocks having fundamental frequencies around, and less than, the resonance frequency.

With shocks having fundamental frequencies around 8 and $16 \mathrm{~Hz}$, there was less discomfort from low, middle, and high magnitude shocks with the $80-\mathrm{mm}$ foam than the $40-\mathrm{mm}$ foam (Figure 8). However, except with some 16-Hz shocks, the subjective SEAT values were still close to $100 \%$ and so neither foam greatly reduced the discomfort caused by the shocks.

\section{FIGURE 8 ABOUT HERE}

\subsection{Use of the subjective SEAT value}

Even if a foam cushion had attenuated all of a shock the subjective SEAT value would not have been $0 \%$, because feeling the shock at the feet would have contributed to discomfort (with both the rigid seat and the foam cushion). At frequencies greater than about $8 \mathrm{~Hz}$, the body locations experiencing greatest discomfort during vertical vibration or shock tend to be the legs and the feet (Zhou and Griffin, 2014, Ahn and Griffin, 2008; Basri and Griffin, 2014). At frequencies greater than about $10 \mathrm{~Hz}$, the number of subjects indicating the feet or the calves as prime locations of greatest discomfort is greater when sitting on a soft seat than when sitting on a rigid seat - because a soft seat reduces the transmission of vertical vibration to the upper body at these frequencies (Basri and Griffin, 2014).

The subjective SEAT values show that the transmissibility of a seat does not give a direct indication of the extent to the seat will have a beneficial or detrimental effect on discomfort when exposed to mechanical shocks. As may be expected, the frequency content of a shock 
determines both its transmission through a seat and the discomfort caused by the transmitted vibration.

\subsection{Measured SEAT values}

The transmissibilities obtained with random vibration indicated resonances in the range 4 to 7 $\mathrm{Hz}$ for the $40-\mathrm{mm}$ foam cushion and 3 to $5 \mathrm{~Hz}$ for the $80-\mathrm{mm}$ foam cushion, depending on the subject and the magnitude of vibration (Figure 3 shows the median transmissibility from the 18 subjects). However, the SEAT values show maximum values for shocks having fundamental frequencies in the ranges 3 to $4 \mathrm{~Hz}$ and 2 to $3 \mathrm{~Hz}$, for the $40-\mathrm{mm}$ and $80-\mathrm{mm}$ foam cushions, respectively (Figure 7). Some of this difference can be attributed to nonlinearity and differences between the magnitudes of the random vibration and the magnitudes of the mechanical shocks. A greater difference is due to the transmissibilities in Figure 3 reflecting the response at each frequency of vibration while the SEAT values in Figure 7 reflect the response over a range of frequencies around the fundamental frequency of each shock. Such differences between transmissibility and SEAT values should be expected because a SEAT value is influenced by both the transmissibility and the frequency weighting at frequencies additional to the fundamental frequency of the shock. When assessing or optimising a seat for an environment with vertical shocks or complex vibration, the SEAT value will give a more reliable indication of seat dynamic performance than the seat transmissibility.

Measured SEAT values reflect the acceleration measured in the SIT-pad, but the body was not continuously in contact with the SIT-pad when the acceleration of the low frequency shocks with larger displacements approached $1 \mathrm{~g}$. For these motions $\left(1.0\right.$ and $2.0 \mathrm{~Hz}$ with $2.0 \mathrm{~ms}^{-2}$ r.m.s.) there was also a subsequent impact that was reflected in the acceleration of the SITpad. For both foam cushions, these impacts caused the measured SEAT values to be appreciably greater than the subjective SEAT values (Figure 6 bottom row). The duration of separation between a subject and a SIT-pad will depend on the frequency and the magnitude of the motion as well as the dynamic response of the foam cushion. The severity of the impact is dependent on the relative velocity of the subject and the SIT-pad at the moment of impact and the compliance of the support beneath the SIT-pad. The impact therefore depends on the waveform of the shock motion, but for the same waveform the impact will be greater with shocks having lower fundamental frequencies.

\subsection{Predicted SEAT values}

The 3-degree-of-freedom model predicted similar acceleration in the SIT-pad and similar SEAT values to those measured by the SIT-pad, except for the lowest frequency highest magnitude shocks where the predicted SEAT values were lower than the measured SEAT values (Figure 7 ). This is consistent with the simple linear model not being sufficient when the body rose off 
the seat and subsequently fell back onto the SIT-pad. With a similar model of the vertical apparent mass of the body and similar mechanical shocks, a median difference as high as $50 \%$ has been reported between predicted and measured apparent mass (Zhou and Griffin, 2017b).

In addition to the model not predicting the body leaving the seat, the model did not predict the non-linearity of the biodynamic responses evident in the reduction in the resonance frequency with increasing magnitude of vibration (Figure 3). Although the measured and predicted SEAT values shown in Figure 7 have encouraging agreement, they would likely be closer if the parameters of the model had been adjusted to take account of the nonlinearity in the biodynamic responses of the body to vertical vibration and mechanical shocks (Matsumoto and Griffin, 2005; Zhou and Griffin, 2017b; Tufano and Griffin, 2013; Fairley and Griffin, 1989).

\subsection{Comparisons of measured SEAT values, predicted SEAT values, and subjective SEAT values}

With most frequencies and magnitudes of shock, the measured SEAT values and the predicted SEAT values were similar to the subjective SEAT values (Figure 6).

The measured SEAT value was a good indicator of the effect of the seat on the discomfort caused by low magnitude and middle magnitude shocks, consistent with previous studies using vibration. With three different seats ('soft', 'intermediate' and 'hard') Basri and Griffin (2014) found that SEAT values for 12 subjects predicted well the discomfort caused by vertical sinusoidal vibration in the frequency range 1 to $20 \mathrm{~Hz}$ with magnitudes in the range 0.2 to 1.6 $\mathrm{ms}^{-2}$ r.m.s. For the vertical vibration on 16 car seats, Niekerk et al. (2003) found that the average subjective ratings of 6 subjects were correlated with the average estimated SEAT values, with correlation coefficients between individual subjective ratings and measured SEAT values in the range 0.3 to about 0.8 .

Consistent with the first hypothesis, with shocks having a high magnitude (e.g., $2 \mathrm{~ms}^{-1.75}$ ) and low fundamental frequency $(1.0$ to $2.0 \mathrm{~Hz}$ ) the 'measured SEAT value' overestimated the 'subjective SEAT value' (by up to $50 \%$; Table 2 ) because the body 'left the seat' and the measured SEAT value was influenced by a shock as the body subsequently impacted on the SIT-pad resting on the seat surface.

The findings suggest it may sometimes be appropriate to remove the acceleration due to the body impacting with a SIT-pad resting on a soft seat when evaluating motions and predicting human responses to high magnitude shocks. This may allow measured SEAT values to indicate the effects of a seat on discomfort with the highest magnitudes of shock, but only if the seat is sufficiently soft for the impact to be of little importance. If a vertical shock causes a 
person to rise off a seat that is rigid (or 'hard'), the subsequent impact with the seat could be a significant source of discomfort and even injury. A SIT-pad attached to a rigid seat would indicate the motion of the rigid seat and not the shock to the human body. It may be concluded that the methods defined in current standards are not sufficient to indicate when such impacts occur, when they become important, or how their severity can be best estimated.

Consistent with the second hypothesis, with shocks having a high magnitude $\left(2 \mathrm{~ms}^{-1.75}\right)$ and low fundamental frequency $(1.0$ to $2.0 \mathrm{~Hz}$ ), the 'subjective SEAT values' were better approximated by the 'predicted SEAT values' than the 'measured SEAT values'. The median percentage differences between 'subjective SEAT values' and 'predicted SEAT values' were less than $\pm 5 \%$ but median percentage differences between 'subjective SEAT values' and 'measured SEAT values' were up to $50 \%$ (Tables 2 and 3). The predicted SEAT values were closer because the impact with the SIT-pad on the foam cushion had little effect on subjective responses and was not predicted by the linear model.

\section{Conclusions}

SEAT values reflect the effects of cushions on the discomfort caused by vertical mechanical shocks and they can be used to optimise the dynamic responses of seats to vertical mechanical shocks.

For all frequencies of low magnitude shock and middle magnitude shock, the SEAT values predicted by a 3-degree-of-freedom model were similar to measured SEAT values.

If people are exposed to shocks that cause them to rise off a soft seat (e.g., low frequency motions with peak acceleration around $1 \mathrm{~g}$ or greater) and they subsequently impact with the soft seat, the SEAT values predicted by a simple mathematical model may be more accurate than the SEAT values measured using an accelerometer on the seat surface, which can be unduly affected by the impact with the seat. However, if the seat is rigid or hard, signals from an accelerometer on the seat surface will underestimate such impacts that can cause severe discomfort and injury.

\section{Acknowledgements}

This work was undertaken on contract ROD - HQ SG 34/02/08/05 in association with the Institute of Naval Medicine. The assistance of Dr GS Paddan is gratefully acknowledged.

\section{References}

Ahn S.J., Griffin M.J., 2008. Effects of frequency, magnitude, damping, and direction on the discomfort of vertical whole-body mechanical shocks. Journal of Sound and Vibration. 311, 485-497.

Basri B., Griffin M.J., 2014. The application of SEAT values for predicting how compliant seats with backrests influence vibration discomfort. Applied Ergonomics. 45, 6, 1461-1474. 
British Standards Institution, 1987. Guide to Measurement and evaluation of human exposure to whole-body mechanical vibration and repeated shock. BS 6841-1:1987.

Corbridge C., Griffin M.J., 1986. Vibration and comfort: vertical and lateral motion in the range 0.5 to $5 \mathrm{~Hz}$. Ergonomics. 29, 2, 249-272.

Ebe K., Griffin M.J., 2000. Quantitative prediction of overall seat discomfort. Ergonomics. 43, 6, 791-806.

Fairley T.E., Griffin M.J., 1989. The apparent mass of the seated human body: vertical vibration. Journal of Biomechanics. 22, 2, 81-94.

Griffin M.J., 1978. The evaluation of vehicle vibration and seats. Applied Ergonomics. 9, (1), $15-21$.

Griffin M.J., 2007. Discomfort from feeling vehicle vibration. Vehicle System Dynamics. 45, 7, 679-698.

Griffin M.J., Whitham E.M., Parsons K.C., 1982. Vibration and comfort. I. Translational seat vibration. Ergonomics, 25, 7, 603-630.

International Organization for Standardization, 1997. Mechanical vibration and shock Evaluation of human exposure to whole-body vibration - Part 1. BS ISO 2631:1997.

Matsumoto Y., Griffin M.J., 2005. Nonlinear subjective and biodynamic responses to continuous and transient whole-body vibration in the vertical direction. Journal of Sound and Vibration. 287, 4-5, 919-937.

Miwa T., 1967. Evaluation methods for vibration effect. Part 1. Measurements of threshold and equal sensation contours of whole-body for vertical and horizontal vibrations. Industrial Health, 5, 183-205.

Morioka M., Griffin M.J., 2006. Magnitude-dependence of equivalent comfort contours for foreand-aft, lateral and vertical whole-body vibration. Journal of Sound and Vibration. 298, 755-772.

Rezali, K. A. M., and M. J. Griffin. 2016. Transmission of Vibration through Gloves: Effects of Material Thickness. Ergonomics 59 (8): 1026-1037.10.

Thuong O., Griffin M.J., 2011a. The vibration discomfort of standing persons: $0.5-16-\mathrm{Hz}$ foreand-aft, lateral, and vertical vibration. Journal of Sound and Vibration. 330, 816-826.

Thuong O., Griffin M.J., 2011b. The vibration discomfort of standing persons: evaluation of random and transient motions. Ergonomics. 54, 1228-1239.

Toward M.G.R., Griffin M.J., 2011. The transmission of vertical vibration though seats: Influence of the characteristics of the human body. Journal of Sound and Vibration. 330, 6526-6543.

Tufano S., Griffin M.J., 2013. Nonlinearity in the vertical transmissibility of seating: the role of the human body apparent mass and seat dynamic stiffness. Vehicle System Dynamics. $51,122-138$.

Van Niekerk J.L., Pielemeier W.J., Greenberg J.A., 2003. The use of seat effective amplitude transmissibility (SEAT) values to predict dynamic seat comfort. Journal of Sound and Vibration. 260, 5, 867-888.

Wei L., Griffin M.J., 1998. The prediction of seat transmissibility from measures of seat impedance. Journal of Sound and Vibration. 214, 1, 121-137.

Whitham E.M., Griffin M.J., 1977. Measuring vibration on soft seats. Society of Automotive Engineers. SAE Paper 770253. International Automotive Engineering Congress and Exposition, Detroit.

Zhou Z., Griffin M.J., 2014. Response of the seated human body to whole-body vertical vibration: Discomfort caused by sinusoidal vibration. Ergonomics. 57 (5), 693-713. 
Zhou Z., Griffin M.J., 2017a. Response of the seated human body to whole-body vertical vibration: Discomfort caused by mechanical shocks. Ergonomics. 60, 3, 347-357.

Zhou Z., Griffin M.J., 2017b. Response of the seated human body to whole-body vertical vibration: Biodynamic responses to mechanical shocks. Ergonomics. 60, 3, 333-346. 


\section{Figure captions}

Figure 1 Example of the shock acceleration waveform and the corresponding displacement waveform. Example shock has a fundamental frequency of $2 \mathrm{~Hz}$.

Figure 2 Subject on a rigid seat in a comfortable upright posture (left), on a foam cushion (centre). Three degree-of-freedom model of the person cushion system (right).

Figure 3 Comparison of the moduli of the median vertical transmissibility of the $40-\mathrm{mm}$ foam cushion and the $80-\mathrm{mm}$ foam cushion measured with vertical random vibration at $1.0 \mathrm{~ms}^{-2}$ r.m.s. (top) and the effect of the magnitude of vibration on the median foam transmissibility (bottom).

Figure 4 Moduli and phases of the predicted transmissibility and the measured transmissibility of the 40-mm foam cushion (right) and $80-\mathrm{mm}$ foam cushion (left) for one subject and random vibration at $1.0 \mathrm{~ms}^{-2}$ r.m.s.

Figure 5 Measured vertical shock acceleration waveforms for one subject and acceleration waveforms predicted by the three degree-of-freedom model. Subject on $80-\mathrm{mm}$ foam cushion. Low magnitude shocks (left) high magnitude shocks (right), shock fundamental frequency of 2 $\mathrm{Hz}$ (top) and $16 \mathrm{~Hz}$ (bottom).

Figure 6 Mean measured SEAT values, predicted SEAT values, and subjective SEAT values with vertical mechanical shocks at three magnitudes: $40-\mathrm{mm}$ foam (left) and $80-\mathrm{mm}$ foam (right).

Figure 7 Median predicted SEAT values and median measured SEAT values with vertical mechanical shocks at three magnitudes: $40-\mathrm{mm}$ foam (left) and $80-\mathrm{mm}$ foam (right).

Figure 8 Effect of foam thickness on subjective SEAT values.

\section{Table captions}

Table 1 Unweighted peak accelerations for each magnitude and each fundamental frequency of the input shocks with frequency-weighted vibration dose values of $0.5,1.0$ and $2.0 \mathrm{~ms}^{-1.75}$.

Table 2 Median percentage differences between measured SEAT values and subjective SEAT values for the 40-mm foam cushion and the $80-\mathrm{mm}$ foam cushion; ${ }^{*} p<0.05$ and ${ }^{* *} p<$ 0.005 (Wilcoxon matched-pairs signed ranks test). Negative differences indicate subjective SEAT values greater than measured SEAT values.

Table 3 Median percentage differences between predicted SEAT values and subjective SEAT values for the 40-mm foam cushion and the 80 -mm foam cushion; ${ }^{*} p<0.05$ and ${ }^{* *} p<$ 0.005 (Wilcoxon matched-pairs signed ranks test). Negative differences indicating that the subjective SEAT values were greater than the predicted SEAT values.

Table 4 Median percentage differences between predicted SEAT values and measured SEAT values for the 40-mm foam cushion and the 80 -mm foam cushion; ${ }^{*} p<0.05$ and ${ }^{* *} p<$ 0.005 (Wilcoxon matched-pairs signed ranks test). 

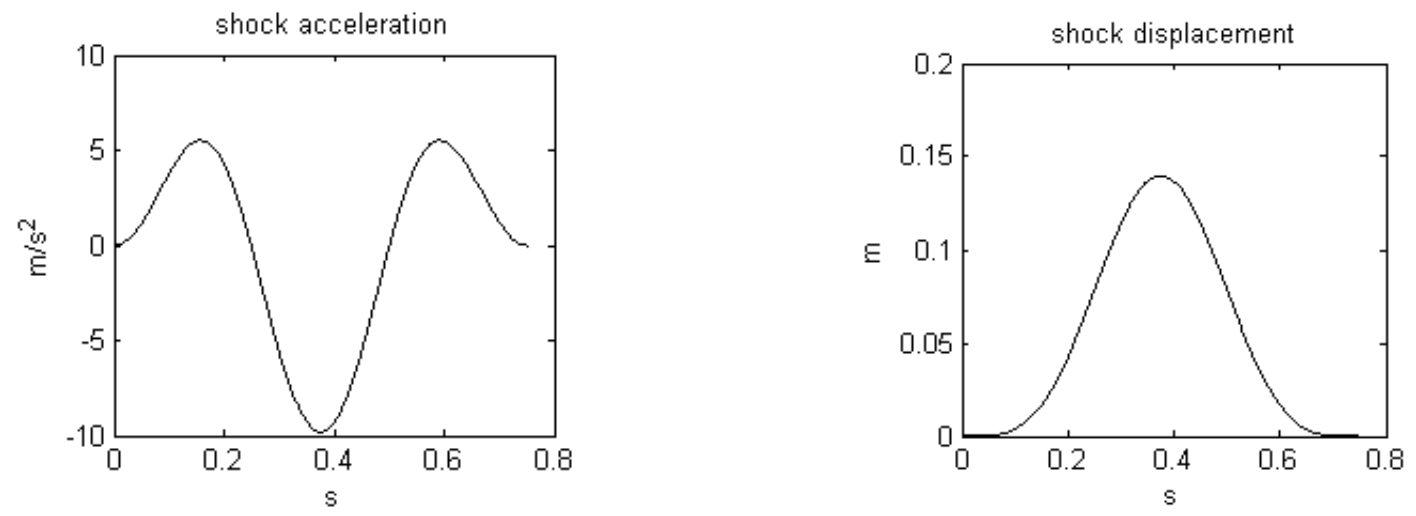

Figure 1 Example of the shock acceleration waveform and the corresponding displacement waveform. Example shock has a fundamental frequency of $2 \mathrm{~Hz}$. 


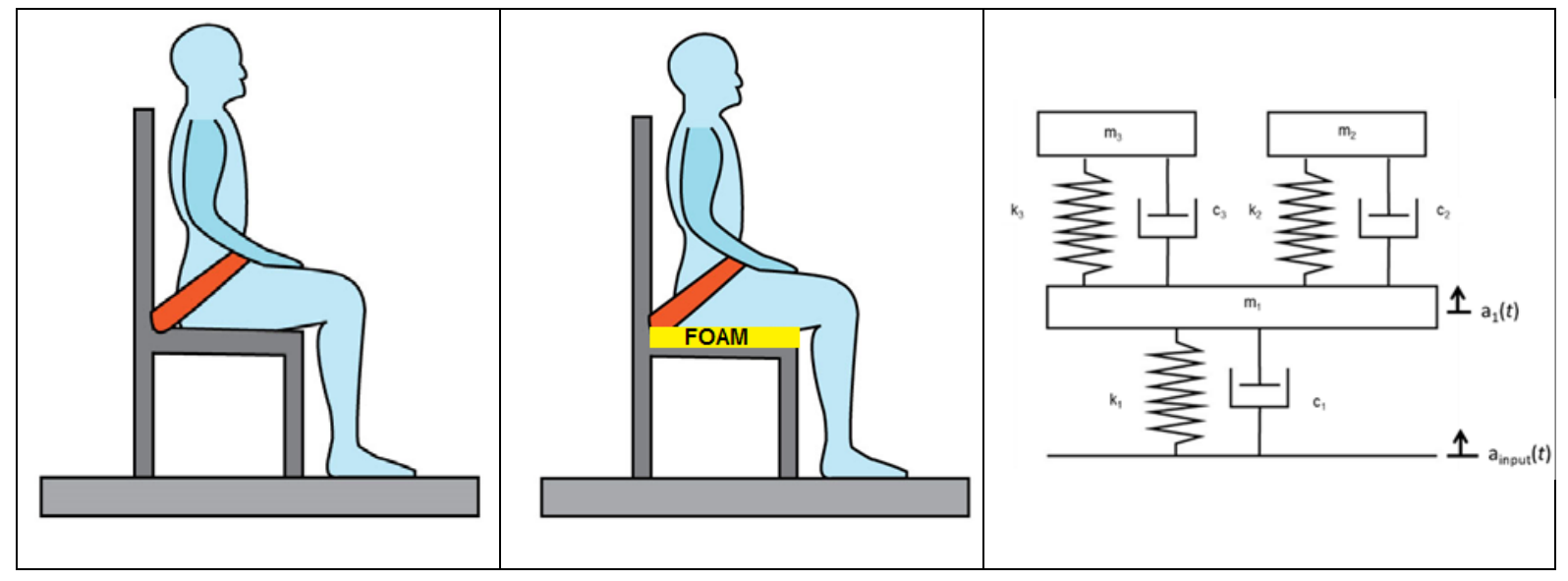

Figure 2 Subject on a rigid seat in a comfortable upright posture (left), on a foam cushion (centre). Three degree-of-freedom model of the person cushion system (right). 

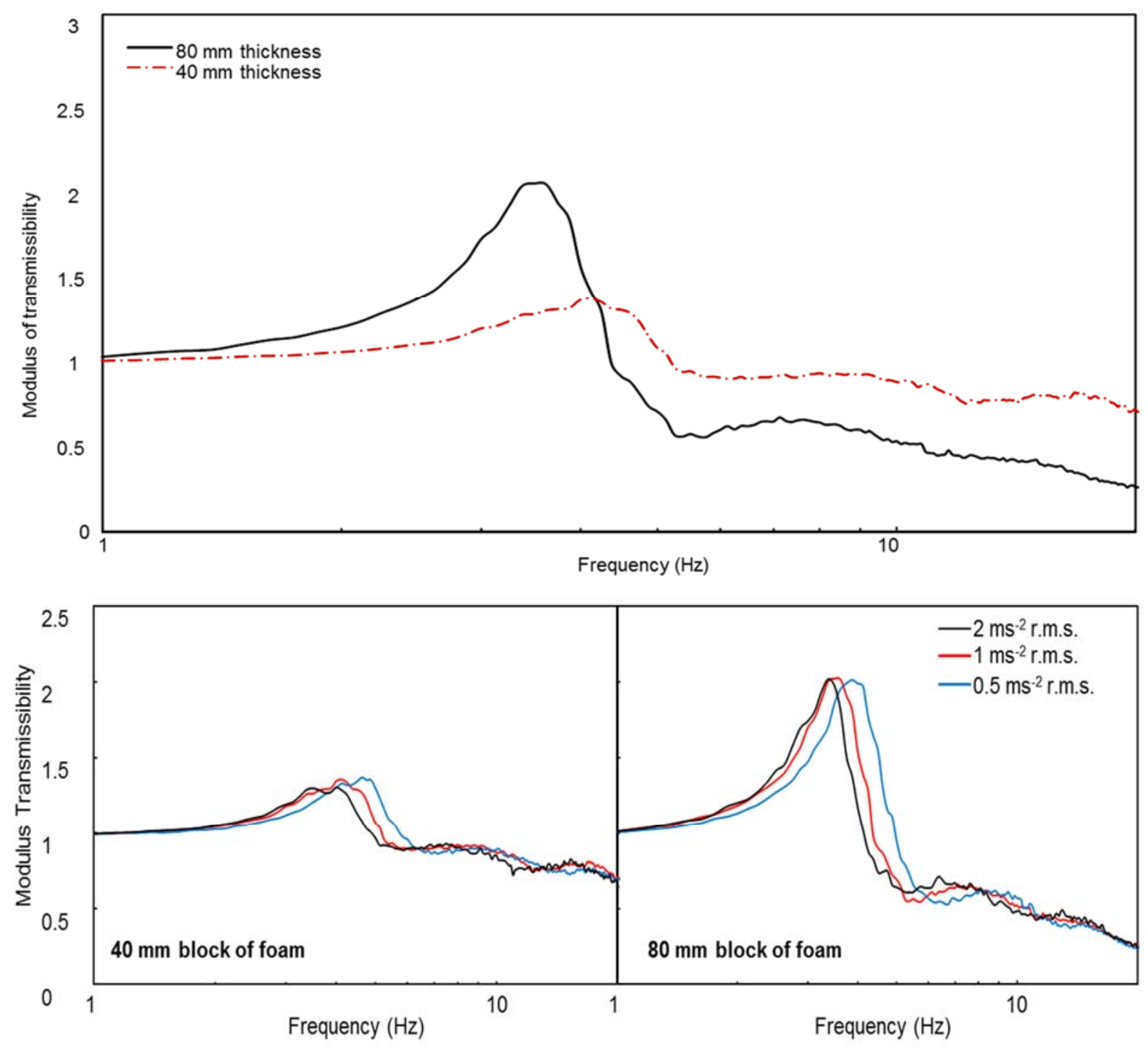

Figure 3 Comparison of the moduli of the median vertical transmissibility of the $40-\mathrm{mm}$ foam cushion and the $80-\mathrm{mm}$ foam cushion measured with vertical random vibration at $1.0 \mathrm{~ms}^{-2}$ r.m.s. (top) and the effect of the magnitude of vibration on the median foam transmissibility (bottom). 

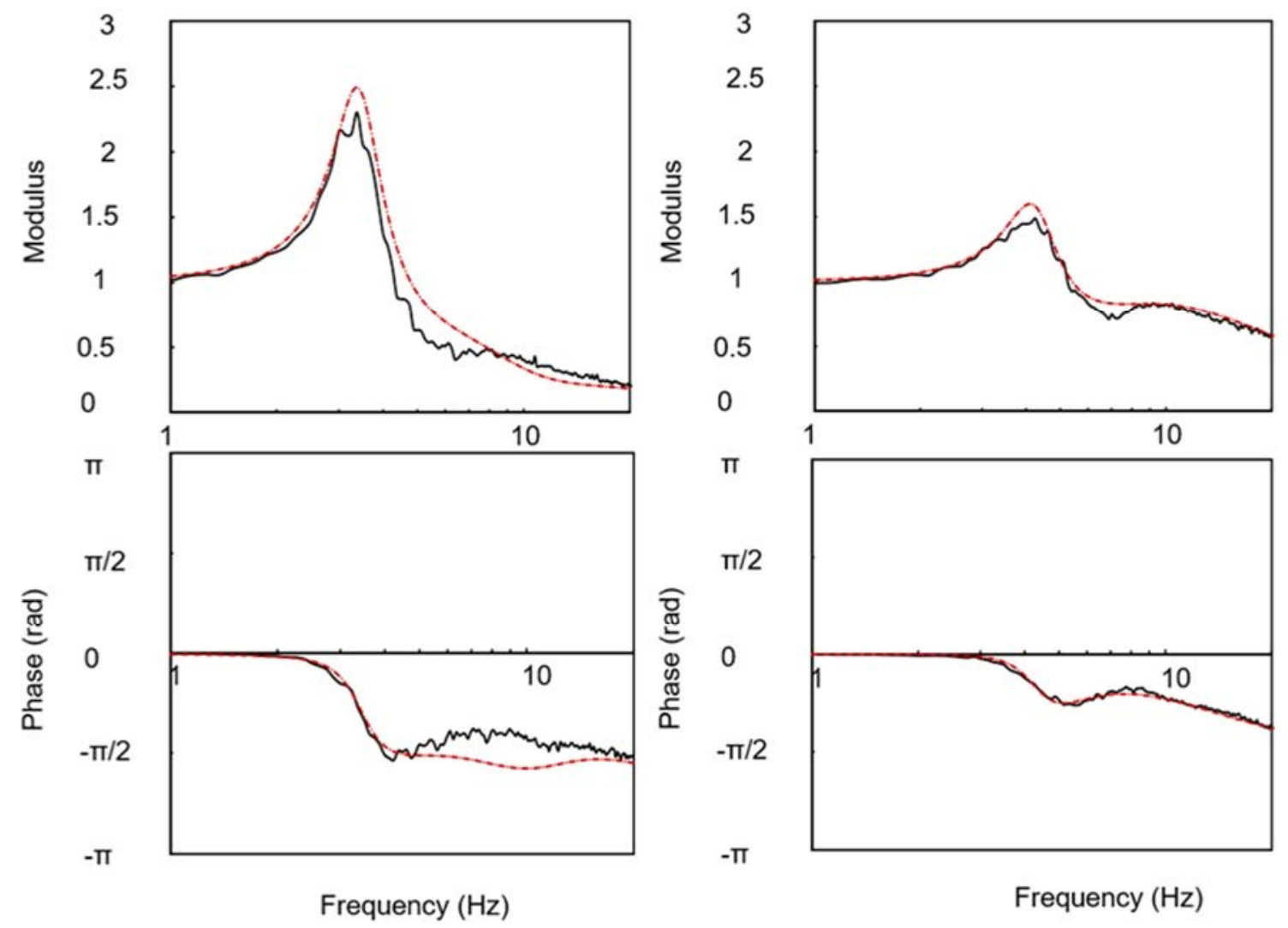

Figure 4 Moduli and phases of the predicted transmissibility and the measured transmissibility of the $40-\mathrm{mm}$ foam cushion (right) and $80-\mathrm{mm}$ foam cushion (left) for one subject and random vibration at $1.0 \mathrm{~ms}^{-2}$ r.m.s. 

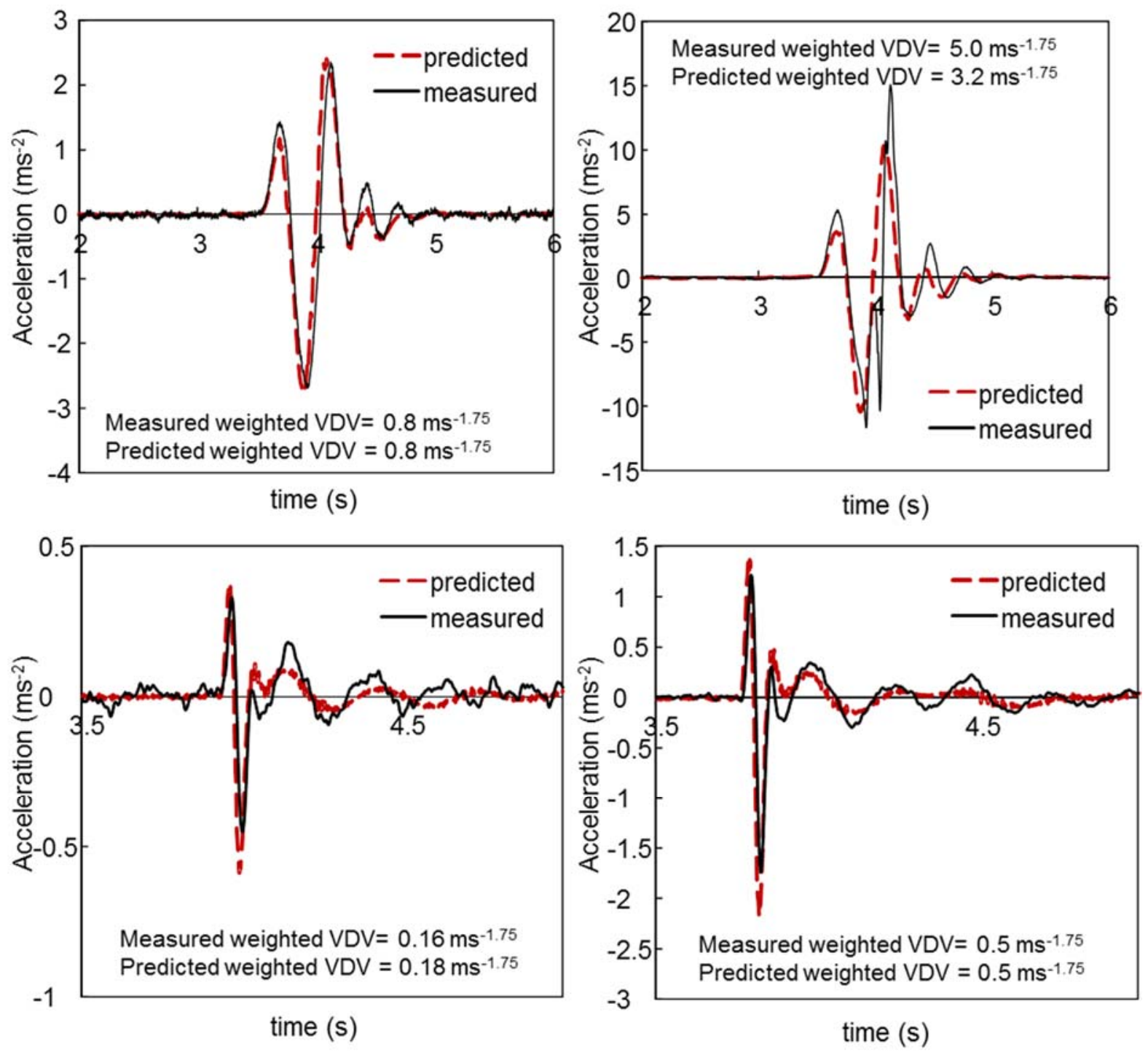

Figure 5 Measured vertical shock acceleration waveforms for one subject and acceleration waveforms predicted by the three degree-of-freedom model. Subject on 80-mm foam cushion. Low magnitude shocks (left) high magnitude shocks (right), shock fundamental frequency of 2 $\mathrm{Hz}$ (top) and $16 \mathrm{~Hz}$ (bottom). 

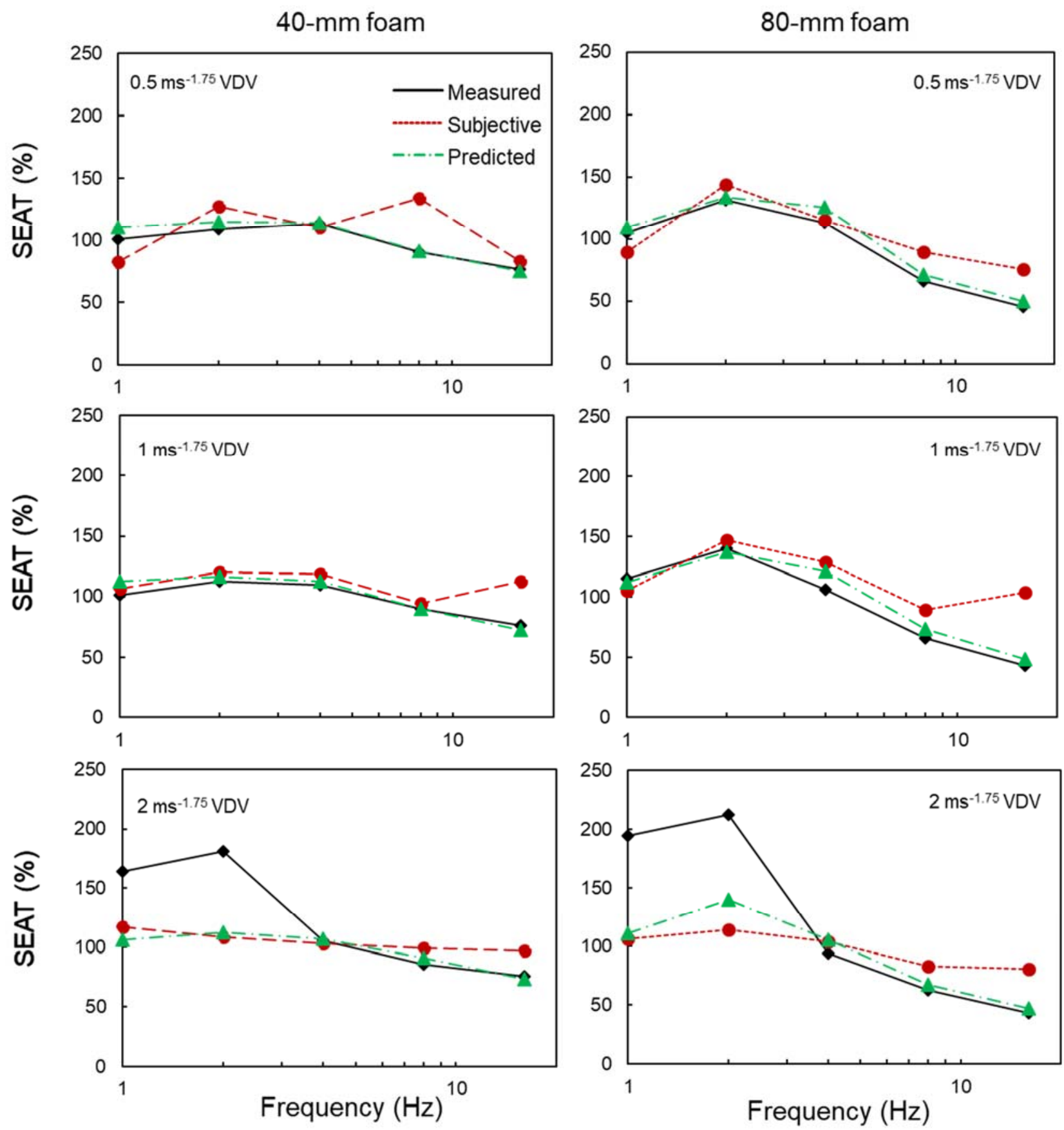

Figure 6 Mean measured SEAT values, predicted SEAT values, and subjective SEAT values with vertical mechanical shocks at three magnitudes: 40-mm foam (left) and 80-mm foam (right). 

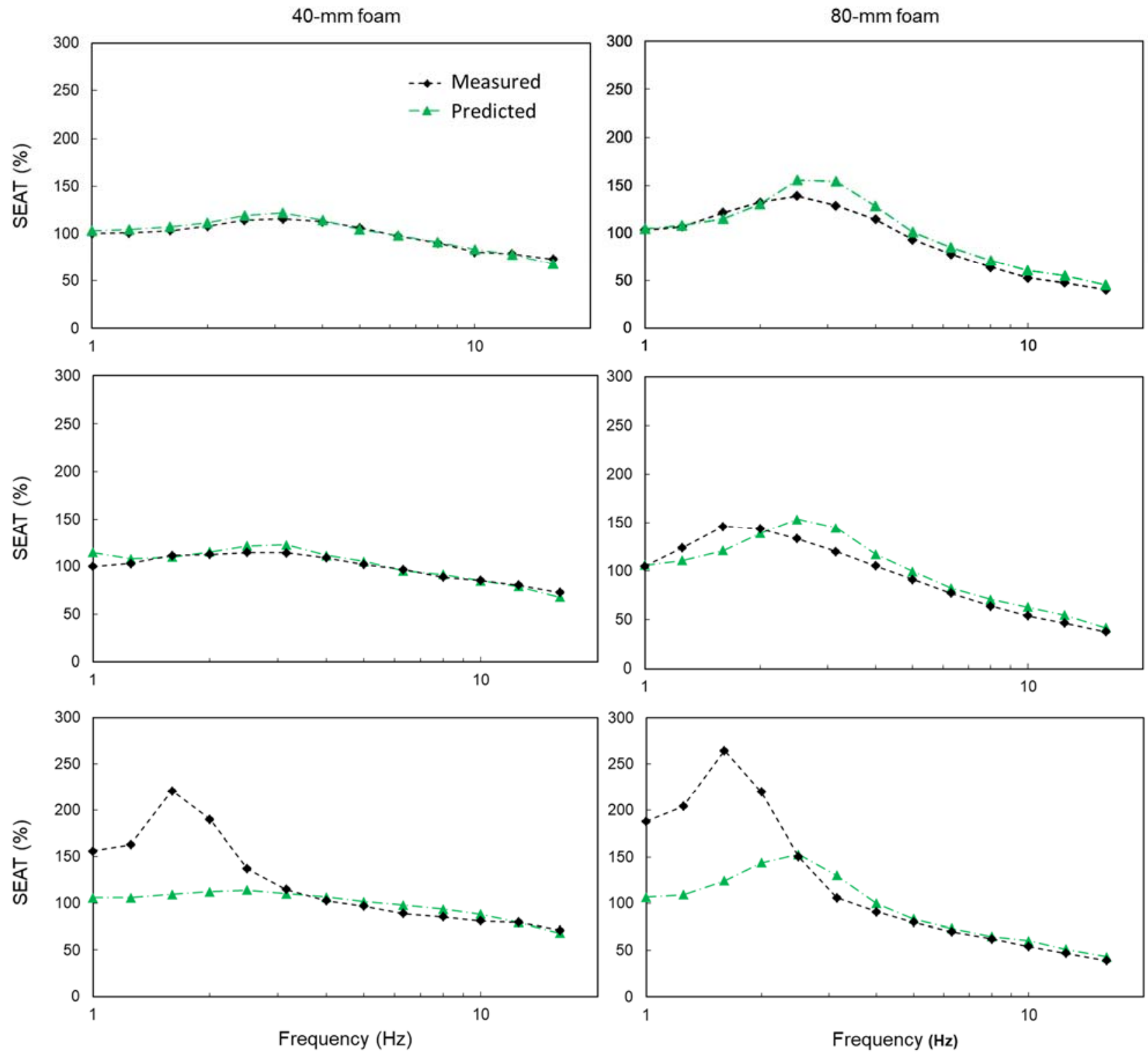

Figure 7 Median predicted SEAT values and median measured SEAT values with vertical mechanical shocks at three magnitudes: $40-\mathrm{mm}$ foam (left) and $80-\mathrm{mm}$ foam (right). 
Published as: Patelli, G. and Griffin, M.J (2019)

Effects of seating on the discomfortcaused by mechanical shocks: Measurement and prediction of SEAT values. Applied Ergonomics 74, $134-144$.

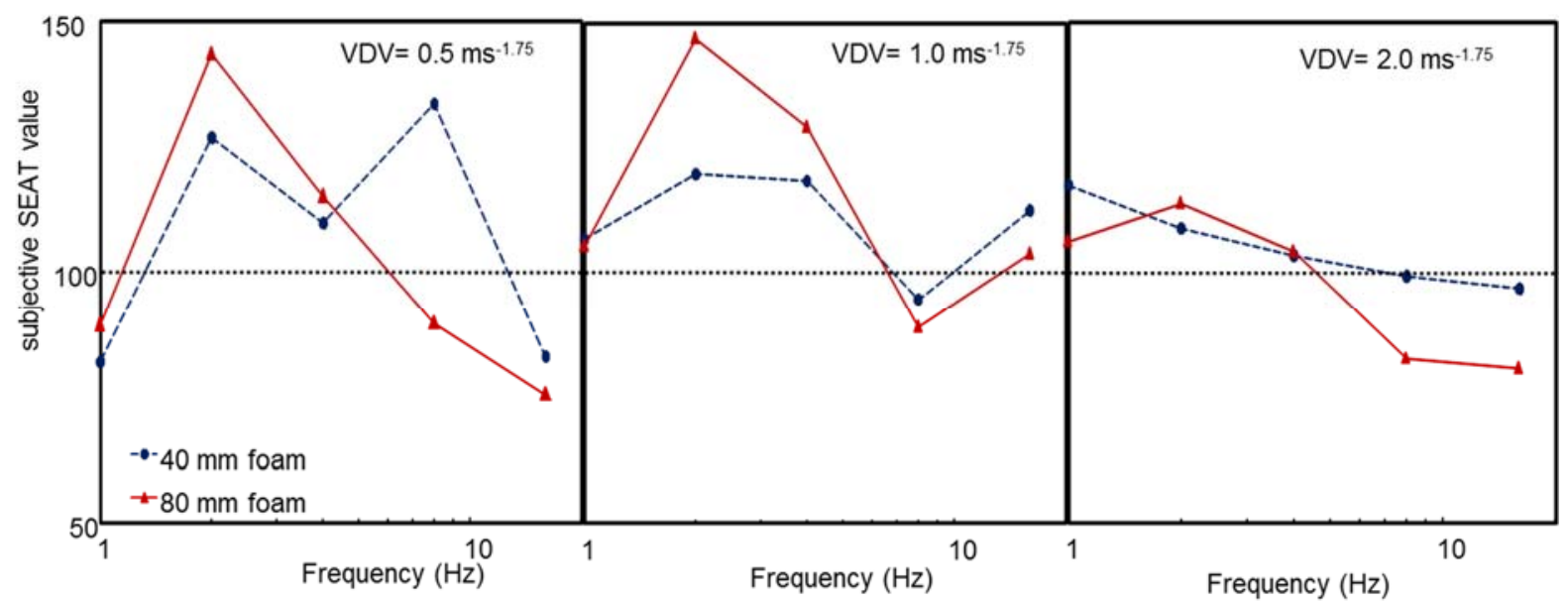

Figure 8 Effect of foam thickness on subjective SEAT values. 
Table 1 Unweighted peak accelerations for each magnitude and each fundamental frequency of the input shocks with frequency-weighted vibration dose values of $0.5,1.0$ and $2.0 \mathrm{~ms}^{-1.75}$.

\begin{tabular}{|c|c|c|c|}
\hline \multirow{2}{*}{ Frequency $(\mathrm{Hz})$} & \multicolumn{3}{|c|}{ Frequency-weighted vibration dose value $\left(\mathrm{ms}^{-1.75}\right)$} \\
\cline { 2 - 4 } & 0.5 & 1.0 & 2.0 \\
\cline { 2 - 4 } & \multicolumn{3}{|c|}{ unweighted peak acceleration $\left(\mathrm{ms}^{-2}\right)$} \\
\hline 1.0 & 2.0 & 4.0 & 8.0 \\
\hline 1.25 & 2.1 & 4.1 & 8.2 \\
\hline 1.6 & 2.1 & 4.1 & 8.3 \\
\hline 2.0 & 1.9 & 3.9 & 7.7 \\
\hline 2.5 & 1.7 & 3.4 & 6.8 \\
\hline 3.15 & 1.4 & 2.9 & 5.7 \\
\hline 4.0 & 1.3 & 2.5 & 5.1 \\
\hline 5.0 & 1.2 & 2.4 & 4.8 \\
\hline 6.3 & 1.2 & 2.4 & 4.8 \\
\hline 8.0 & 1.3 & 2.6 & 6.1 \\
\hline 10.0 & 1.4 & 2.8 & 5.6 \\
\hline 12.5 & 1.6 & 3.1 & 6.3 \\
\hline 16.0 & 1.8 & 3.7 & 7.3 \\
\hline
\end{tabular}


Table 2 Median percentage differences between measured SEAT values and subjective SEAT values for the $40-\mathrm{mm}$ foam cushion and the $80-\mathrm{mm}$ foam cushion; ${ }^{*} p<0.05$ and ${ }^{* *} p$ $<0.005$ (Wilcoxon matched-pairs signed ranks test). Negative differences indicate subjective SEAT values greater than measured SEAT values.

\begin{tabular}{|c|c|c|c|c|c|}
\hline \multirow{6}{*}{$\begin{array}{c}\text { Weighted VDV } \\
\left(\mathrm{ms}^{-1.75}\right)\end{array}$} & 1.0 & 2.0 & 4.0 & 8.0 & 16 \\
\hline 0.5 & $23.8^{*}$ & -4.1 & 7.3 & -10.2 & $-14.0^{*}$ \\
\hline 1.0 & -2.5 & 7.7 & 1.0 & 6.6 & $-38.1^{* *}$ \\
\hline 2.0 & $32.8^{* *}$ & $39.5^{* *}$ & -1.6 & -9.6 & $-40.5^{* *}$ \\
\hline \multicolumn{7}{|c|}{ 40-mm block of foam } \\
\hline $\begin{array}{c}\text { Weighted VDV } \\
\left(\mathrm{ms}^{-1.75}\right)\end{array}$ & 1.0 & 2.0 & 4.0 & 8.0 & 16 \\
\hline 0.5 & 11.0 & 1.4 & -0.2 & $-36.5^{* *}$ & $-72.1^{* *}$ \\
\hline 1.0 & 8.2 & 11.7 & -12.3 & 5.1 & $-107.5^{* *}$ \\
\hline 2.0 & $47.5^{* *}$ & $44.2^{* *}$ & -6.8 & $-41.5^{* *}$ & $-53.7^{* *}$ \\
\hline
\end{tabular}


Table 3 Median percentage differences between predicted SEAT values and subjective SEAT values for the $40-\mathrm{mm}$ foam cushion and the $80-\mathrm{mm}$ foam cushion; ${ }^{*} p<0.05$ and ${ }^{* *} p<$ 0.005 (Wilcoxon matched-pairs signed ranks test). Negative differences indicating that the subjective SEAT values were greater than the predicted SEAT values.

\begin{tabular}{|c|c|c|c|c|c|}
\hline \multicolumn{7}{|c|}{ 40-mm block of foam } \\
\hline $\begin{array}{c}\text { Weighted VDV } \\
\left(\mathrm{ms}^{-1.75}\right)\end{array}$ & 1.0 & 2.0 & 4.0 & 8.0 & 16 \\
\hline 0.5 & $27.3^{*}$ & -1 & -0.4 & -10.4 & -12.5 \\
\hline 1.0 & 6.8 & 9.1 & 4.7 & 6.4 & $-37.5^{*}$ \\
\hline 2.0 & 0.4 & 4.1 & -4.8 & -7.6 & $-32.6^{*}$ \\
\hline \multicolumn{7}{|c|}{$80-\mathrm{mm}$ block of foam } \\
\hline $\begin{array}{c}\text { Weighted VDV } \\
\left(\mathrm{ms}^{-1.75}\right)\end{array}$ & 1.0 & 2.0 & 4.0 & 8.0 & 16 \\
\hline 0.5 & $14.4^{*}$ & 4.1 & 13.2 & $-27.8^{*}$ & $-56.5^{*}$ \\
\hline 1.0 & 2.2 & 5.4 & 3.6 & 13.1 & $-73.3^{* *}$ \\
\hline 2.0 & 4.6 & $17.5^{* *}$ & 7.7 & $-23.1^{* *}$ & $-66.3^{* *}$ \\
\hline
\end{tabular}


Table 4 Median percentage differences between predicted SEAT values and measured SEAT values for the $40-\mathrm{mm}$ foam cushion and the $80-\mathrm{mm}$ foam cushion; ${ }^{*} p<0.05$ and ${ }^{* *} p<$ 0.005 (Wilcoxon matched-pairs signed ranks test).

\begin{tabular}{|c|c|c|c|c|c|c|c|c|c|c|c|c|c|}
\hline \multicolumn{10}{|c|}{ 40-mm foam cushion } \\
\hline $\begin{array}{c}\text { Weighted } \\
\text { VDV } \\
\left(\mathrm{ms}^{-1.75}\right)\end{array}$ & 1.0 & 1.25 & 1.6 & 2.0 & 2.5 & 3.15 & 4.0 & 5.0 & 6.3 & 8.0 & 10 & 12.5 & 16 \\
\hline 0.5 & $-2.7^{* *}$ & $-3.7^{* *}$ & $-3.9^{* *}$ & $-3.4^{* *}$ & -2.9 & -2.1 & -0.2 & 2.00 & -3.4 & -1.9 & -4.2 & -1.6 & $3.5^{*}$ \\
\hline 1.0 & $-14.5^{* *}$ & $-4.4^{* *}$ & 2.5 & -1.9 & $-4.3^{* *}$ & -5.3 & -2.0 & 1.5 & -0.3 & -3.7 & -0.6 & 0.4 & $6.8^{* *}$ \\
\hline 2.0 & $31.6^{* *}$ & $34.8^{* *}$ & $50.1^{* *}$ & $40.5^{* *}$ & $16.0^{* *}$ & 3.9 & -0.9 & $-5.4^{*}$ & $-6.9^{*}$ & $-8.7^{*}$ & -3.8 & 2.8 & 4.0 \\
\hline \multicolumn{10}{|c|}{$80-\mathrm{mm}$ foam cushion } \\
\hline $\begin{array}{c}\text { Weighted } \\
\text { VDV } \\
\left(\mathrm{ms}^{-1.75}\right)\end{array}$ & 1.0 & 1.25 & 1.6 & 2.0 & 2.5 & 3.15 & 4.0 & 5.0 & 6.3 & 8.0 & 10 & 12.5 & 16 \\
\hline 0.5 & $-2.2^{*}$ & -1.9 & $3.2^{*}$ & 1.3 & $-9.2^{* *}$ & $-20.0^{* *}$ & $-11.3^{* *}$ & $-8.8^{* *}$ & $-9.7^{* *}$ & $-8.1^{* *}$ & $-16.1^{* *}$ & $-15.8^{* *}$ & $-9.3^{* *}$ \\
\hline 1.0 & $-1.7^{*}$ & $10.6^{* *}$ & $16.0^{* *}$ & $3.0^{*}$ & $-14.8^{* *}$ & $-20.9^{* *}$ & $-12.5^{* *}$ & $-5.7^{*}$ & $-8.5^{* *}$ & $-10.7^{* *}$ & $-15.3^{* *}$ & $-19.9^{* *}$ & $-8.7^{* *}$ \\
\hline 2.0 & $42.1^{* *}$ & $44.7^{* *}$ & $52.9^{* *}$ & $35.3^{* *}$ & -4.7 & $-23.4^{* *}$ & $-12.5^{* *}$ & -3.8 & -1.7 & -2.3 & $-10.0^{*}$ & $-16.0^{* *}$ & $-9.1^{*}$ \\
\hline
\end{tabular}

